\title{
Significados de infancia en el marco de la globalización
}

\author{
Teresita de Lourdes Bernal Romero*, Jorge Mario Jaramillo Pérez**, Liliana Mendoza \\ Ramos, María Angélica Pérez Serna, y Ana María Suárez Reyes
}

Recibido: 31 de marzo de 2009 Revisado: 28 de mayo de 2009 Aprobado: 16 de julio de 2009

\section{ReSUMeN}

El objetivo de esta investigación es comprender los significados sobre infancia construidos por niños, niñas, padres de familia y maestros en el contexto de la globalización. La metodología que se utilizó combina elementos de investigación e intervención; la estrategia de investigación que se empleó fue de escenarios conversacionales que se sistematizaron a través de un análisis de contenido de tipo categorial. Los protagonistas de la investigación fueron niños, niñas, padres de familia y maestros de seis colegios de Bogotá de diferentes estratos socioeconómicos. Se concluye que los significados sobre la infancia, en la actualidad, están atravesados por criterios discontinuistas, psicosociales, ideales, de vulnerabilidad y de género. Estos criterios surgen como categorías inductivas de la investigación. En discontinuista se agrupan los significados que comprenden la infancia como etapa. En lo psicosocial, significados relacionados con funciones, derechos y cambios. En ideales significaciones relacionadas con la infancia como época sin problemas. En vulnerabilidad se agrupan significados relacionados con dificultades y minusvalías, y en género diferencias entre niños y niñas.

\section{Palabras clave}

Infancia, globalización, significados.

* Investigadora principal. Docente de la Universidad Santo Tomás. Miembro del grupo de Investigación Infantia. Correo electrónico: teresitabernal@ usantotomas.edu.co, telourdesberna@@ yahoo.es.

** Investigador principal. Docente de La Universidad Santo Tomás. Miembro del grupo de Investigación Infantia. Correo electrónico: jorgejaramillo@ usantotomas.edu.co, jaramillojorgemario@ hotmail.com. 


\title{
Meaning of childhood within the framework of the globalization
}

\author{
Teresita de Lourdes Bernal Romero, Jorge Mario Jaramillo Pérez, \\ Liliana Mendoza Ramos, María Angélica Pérez Serna, y Ana María Suárez Reyes
}

\begin{abstract}
The objective of this investigation is to understand the meaning of childhood that are constructed by children, parents and teachers in the context of the globalization. The methodology used combines both elements of investigation and intervention; the investigation strategy used was of conversational scenes that were systematized through analysis of categorial type content. The investigation subjects were children, parents and teachers of 6 schools in Bogota of differing socio-economic classes. It was concluded that the current meaning of childhood is influenced by random criteria including psycho-social, ideals, vulnerability and gender. These criteria arise as inductive categories of the investigation. The random meanings are therefore grouped so that childhood is understood as a stage while in the psycho-social, meaning is related to functions, rights and changes, ideal meanings are related to childhood as a time without problems. In vulnerability, they group meaning as being related to difficulties and disabilities, and in gender as differences between boys and girls.
\end{abstract} Recibido: 31 de marzo de 2009 Revisado: 28 de mayo de 2009

Key words

Childhood, Globalisation, Meaning. 


\section{Presentación}

La globalización económica, política y cultural que está experimentando el mundo tiene como sustento la extensión del modelo neoliberal del capitalismo, así como un vertiginoso desarrollo de las tecnologías del transporte, la comunicación y la informática. Esta globalización se experimenta en diferentes áreas: económica, cultural, política y social. En esta última la globalización trae consigo una serie de rápidos y profundos cambios en distintas formas de significar y relacionarse. Giddens (1999) enuncia que los cambios más importantes que están sucediendo en el mundo se reflejan en la sexualidad, las relaciones, el matrimonio y las familias: "Hay en marcha una revolución mundial sobre cómo nos concebimos a nosotros mismos y cómo formamos lazos y relaciones con los demás. Es una revolución que avanza desigualmente en diferentes regiones y culturas, con muchas resistencias" (p. 65). Desde esta perspectiva, parece importante hacer un abordaje de la globalización más allá de lo económico, pensando en lo humano. Además, el autor plantea cómo estos cambios se están dando en las concepciones sobre sí mismo y los lazos o relaciones que se construyen con los demás, interés de esta investigación bajo la categoría de significados.

Por otra parte, desde la Convención Internacional de los Derechos del Niño en el año 1989, el tema de la infancia se ha convertido en una prioridad en la agenda de las ciencias sociales de distintos países. En la actualidad, se habla del niño como sujeto de derechos y cómo los derechos de los niños y las niñas priman sobre otros. En psicología el tema de la infancia ha sido tratado desde diferentes teorías, haciendo énfasis en su desarrollo desde la piscología infantil y focalizando en su intervención desde abordajes clínicos. Desde los abordajes de la psicología del desarrollo; Flores (s.f.) enuncia que éstos se han centrado fundamentalmente en la psique:

Se puede decir que conocer seriamente a los infantes, a partir de un niño niña modelo o teóricamente construido por la psicología, se reduce a calificarlo en términos funcionalistas a partir de los conocimientos intelectuales. La psicología infantil ha tendido a reducir el estudio de la infancia a su psiquismo; no importa cuál sea la escuela de pensamiento de referencia, lo ha reducido rápidamente a la génesis compartimentada de este psiquismo, al dominio conceptual de esta génesis, a un sistema, a un modelo normativo (p. 5).

En cuanto a los abordajes clínicos, se puede decir que éstos se centran en la patología y en la técnica para cambiar la condición del niño o de la niña; desde propuestas conductuales e intrapsíquicas.

Ahora bien, si se tienen en cuenta los planteamientos de Giddens sobre globalización (1999) y de Flores (s.f.) sobre las teorías sobre la infancia, en esta investigación, se considera pertinente hacer una lectura de la infancia como agenda social prioritaria, en el marco de la globalización. Esta compresión se centra en lecturas de significados, abandonando teorizaciones intrapsíquicas o conductuales.

Joseff (2005) plantea la relevancia de "los otros" para la construcción del psiquismo del infante. También refiere la importancia del entorno social y la cultura para la construcción de significados, interacciones y socialización de los cuidadores y los niños. Desde esta autor, se puede pensar en la im- 
portancia de realizar abordajes de la infancia desde las voces de los otros, no sólo de las teorías.

Por otra parte, Jurado (2003) ha hecho grandes aportes al estudio de la globalización, la educación y la infancia, al referirse a los cambios que han surgido en las familias como consecuencia de la globalización, que han modificado su papel en la educación y resaltado su papel en la sociedad, obligando a hacer cambios en su forma de participación al reconocerlos como sujetos de derecho, pero sin olvidar sus obligaciones como ciudadanos. Las familias, con los procesos de globalización, están cambiando. ¿Cómo están significando las familias a los niños y a las niñas? y ¿cómo los niños y las niñas se significan a sí mismos?

La investigación realizada por Cari (2005) se dirige a explorar los significados acerca de la infancia en cuatro "superficies", a saber: las políticas educativas y sociales que se desplegaron durante las décadas del ochenta y del noventa en Argentina; explorar las concepciones sobre la infancia indagando las teorías circulantes en el campo educativo, en el campo cultural y en la opinión pública; en tercer lugar, las concepciones acerca de la infancia en la televisión y en la publicidad televisiva y, en cuarto lugar, hacer un acercamiento a la experiencia infantil a partir de la exploración de los consumos culturales infantiles como fenómeno representativo de estas décadas.

En este estudio, más allá de categorías culturales de las teorías y de las políticas se desea acercarse a significaciones de la infancia desde los mismos actores que la rodean: padres, madres, maestros, maestras y, por supuesto, niños y niñas en el contexto actual de globalización. Desde este planteamiento la pregunta que orienta esta investigación es: ¿cuáles son los significados construidos por niños, niñas, padres de familia y maestros sobre infancia, en el contexto de la globalización?

\section{MARCo CONCEPTUAL}

\section{Globalización}

Debido al creciente auge del fenómeno de la globalización, se han hecho evidentes los cambios en la forma de vida de algunas culturas, cambios que están marcados por el surgimiento de nuevas necesidades y la transformación de los significados que las personas construyen acerca de la familia, la educación y la infancia.

Según UNICEF (2006) la globalización "se refiere al proceso de interconexión e interdependencia creciente entre países a través de redes internacionales de actividad, interacción y poder" (p. 3). Estos cambios en lo cultural y social se ven influidos por los crecientes cambios económicos, debido a que "las crisis en los mercados financieros y de productos agrícolas causan desempleo, reducción de ingresos e inestabilidad económica generalizada. En estas condiciones, se debilita la capacidad de las familias para proteger a los niños y las niñas" (UNICEF, p. 9). Es evidente que la globalización económica obliga a las personas a entrar en el mundo de la competitividad, por lo cual ambos padres salen a trabajar dejando a sus hijos al cuidado de otras personas y de la mano de la tecnología que se convierte en el compañero permanente de niños y niñas.

Otros cambios que genera la globalización y que repercuten en las condiciones de vida de la gente así como en la manera de vivir 
y pensar se dan en instituciones modernas tradicionales como la familia, la Iglesia, la empresa, el Estado y los partidos políticos, entre otros (Urreiztieta, 2004). Estas transformaciones del entorno exigen que se realicen lecturas distintas acordes con la manera como se está haciendo evidente el proceso de globalización en cada cultura.

En palabras de Canclini (1999):

Quienes hablan de cómo nuestro tiempo se globaliza narran procesos de intercambio fluidos y de homogenización, naciones que abren sus fronteras y pueblos que se comunican [...] Entre tanto, los estudios sobre migraciones, transculturación y otras experiencias interculturales están llenas de relatos de desgarramiento y conflictos, fronteras que se renuevan y anhelos de restaurar nacionalidades, étnicas o familiares perdidas: intensidad y memoria (p. 34).

Entre estos cambios se encuentran también los que afectan a la educación y a las relaciones que en ella se establecen. Frente a esto, Arias (2007) afirma que la globalización es un fenómeno que hoy hace presencia al margen de nuestras particulares valoraciones sobre su bondad o maldad. En ella la educación de niños, niñas y jóvenes como generaciones que han de afrontar la tarea y consecuencias de este proyecto de globalización-mundialización en un futuro inminente, es fundamental; la educación se constituye en el espacio social privilegiado para generar conciencia de lo que la globalización es, e implica su modus operandi y los tipos de hombres y mujeres que su realización exige.

Aunque la globalización genera grandes avances en cuanto a la tecnología, el acceso a la información, al conocimiento, entre otros, también genera dificultades a los países tercermundistas, como en América Latina, que no pueden entrar a competir de la misma manera que quienes presentan un desarrollo económico para enfrentarse a este fenómeno.

Con respecto a este planteamiento, Arias (2007) afirma que el fenómeno de globalización en la educación:

Genera alta incertidumbre, pues está obligada a decidir a quién educar, si a la totalidad de los ciudadanos y ciudadanas o a unos pocos privilegiados y privilegiadas para que ingresen al mundo global, pues el dominio del conocimiento, que como ya se dijo es condición para ello, hace caducos los oficios no calificados. Éste es un problema que hay que resolver desde el punto de vista ético y social; lo primero, por el derecho a participar en los avances de la humanidad, y lo segundo, porque la igualdad de oportunidades es la base para la democracia (p. 12).

Estas afirmaciones del "derecho a participar en los avances de la humanidad" y "la igualdad de oportunidades" no están totalmente tenidas en cuenta en la globalización, ya que se hacen exigencias que tan solo una parte de la sociedad puede afrontar y, en otros casos, sólo algunos países pueden hacerlo, siendo los más afectados los niños y niñas.

\section{Significados}

Al ser el eje central de este proyecto los cambios surgidos en los significados acerca de la infancia, se hace necesario entender qué son los significados y para esto se retoma a Vygotsky (1996), cuando hace referencia a cómo los niños y las niñas los construyen, y de lo cual dice: "para los niños muy peque- 
ños resulta del todo imposible separar el campo del significado del campo visual, porque existe una íntima función entre el significado y lo que perciben visualmente" (p. 148). Es decir, para los niños y niñas todo lo que existe es lo que tienen al alcance de sus sentidos, lo que pueden ver, tocar, escuchar, degustar y oler, y de esta manera crean conceptos que están relacionados con la realidad que ellos mismos viven.

Esta relación entre la percepción y el significado se ejemplifica claramente en el proceso del desarrollo del lenguaje en los niños. Cuando se le dice a un niño alguna palabra referente a un objeto, el niño comienza a buscarlo. Para Vygotsky (1996), originariamente la palabra significa una determinada localización espacial.

De esta manera se construyen los significados de los niños y niñas, por medio de lo real para ellos, lo que perciben de manera inmediata. Es decir, para los niños primero está el objeto y luego el significado; más adelante están en la capacidad de dar un significado sin necesidad de tener el objeto presente y en ello juega un papel decisivo su progreso en el dominio del lenguaje. Éste comienza teniendo una función exclusivamente social comunicativa para convertirse luego en un medio a través del cual el sujeto se representa el conocimiento y busca autorregularse frente a la acción que sobre él ejerce el medio ambiente. Los significados son, pues, estímulos que crea el sujeto mismo para interpretar la estimulación que recibe y orientarse frente a ella (Wertsch, 1995).

Por su parte, Bruner (1991) reconoce los significados como algo flexible que permite comprender diferentes realidades y que en una cultura pueden llegar a ser ampliamente compartidos. Al igual que Vygotsky, enfatiza en la influencia de la cultura en la construcción y comprensión de los significados, ya que lee al hombre como un ser social que está atravesado por la cultura; cabe aclarar, además, que concibe a la cultura como algo dinámico, es decir, que está en constante movimiento, lo que genera la construcción de nuevos significados que pueden ser resignificados, dependiendo de lo que sucede culturalmente. Esto permite ver de nuevo que el fenómeno de la globalización puede influir y modificar los significados en torno a algunos aspectos de la vida, en este caso de la infancia.

\section{Infancia}

Más que una definición de infancia, es importante mencionar que este estudio se desarrolla desde una perspectiva de derechos, lo cual implica tener en cuenta por lo menos las siguientes premisas:

- El niño, de ser considerado como un objeto de derecho, recupera su condición de sujeto de derechos.

- Todos los actores: familia, estado y sociedad civil son corresponsables en la garantía de los derechos de los niños y las niñas.

- Los programas y planes deben ser desarrollados con la participación activa de los niños y las niñas.

- Los niños y las niñas deben conocer y debatir las intencionalidades del proyecto que se desarrolle.

- Los niños y las niñas tienen derecho a conocer los resultados del proyecto.

- Los proyectos hacia y con los niños deben garantizar los derechos fundamentales. 


\section{Método}

Se trabaja desde un método de investigaciónintervención. Este método garantiza que al tiempo que se produce conocimiento se afecta a la población que se está investigando. Además, al finalizar se plantean lineamientos para un modelo de intervención.

\section{Sujetos}

Los sujetos de esta investigación son niños, niñas, padres, madres de familia, maestros y maestras. Las personas se seleccionan desde instituciones educativas, las cuales se constituyen como centros de operaciones de la investigación. Los estudiantes cursan cuarto o quinto grado; de tal forma que se asegure la facilidad de comunicar y pertenecer a la infancia.

Los criterios de selección tanto de las instituciones como de las personas que participan están dados por: heterogeneidad, disponibilidad y accesibilidad.

- Colegio 1: colegio de carácter privado, mixto, de religiosos. Tienen todos los grados de educación básica y media. Sus estudiantes provienen de estratos 3, 4 y 5. Ubicado en la localidad de Usaquén.

- Colegio 2: colegio de carácter privado, mixto, de laicos. Sus estudiantes provienen de estratos 1 y 2 . Tienen todos los grados de educación básica y media. Ubicado en la localidad de Usme.

- Colegio 3: colegio privado, mixto, de religiosos. Tienen todos los grados de primaria. Sus estudiantes provienen de estratos 2 y 3 . Ubicado en la localidad de Chapinero.

- Colegio 4: carácter privado, mixto, de laicos. Tienen todos los grados de edu- cación básica y media. Sus estudiantes provienen estratos 1 y 2 . Ubicado en la localidad de Usme.

- Colegio 5: colegio privado, femenino, de religiosas. Tienen todos los grados de educación básica y media. Sus estudiantes provienen de estratos 4 y 5 . Ubicado en la localidad de Usme.

- Colegio 6: colegio privado, femenino. Sus estudiantes provienen de estratos 4 y 5. Tienen todos los grados de educación básica y media. Ubicado en la localidad de Suba.

\section{Estrategias investigativas}

Escenarios conversacionales: esta estrategia permite recoger, construir e intervenir los significados y las interacciones de los grupos participantes. Con cada grupo (padres, maestros y niños) se realiza un escenario conversacional, para un total de tres escenarios conversacionales por colegio (total de escenarios conversacionales: dieciocho).

Análisis de contenido de tipo categorial: la información obtenida de la encuesta y de los escenarios conversacionales es organizada y procesada a través de un análisis de contenido de tipo categorial. En éste se tienen en cuenta categorías deductivas e inductivas

\section{Resultados}

La infancia, desde los hallazgos, es definida por los siguientes criterios: discontinuista, psicosocial, ideal, de vulnerabilidad y de género. Estos criterios surgen como categorías inductivas de la investigación. En discontinuista se agrupan los significados que comprenden la infancia como etapa. En lo psicosocial significados relacionados con 
funciones, derechos y cambios. En ideales significaciones relacionadas con la infancia como época sin problemas. En vulnerabilidad se agrupan significados relacionados con dificultades y minusvalías. Y en género se encuentran las comprensiones que marcan diferencias entre niños y niñas.

Desde el criterio discontinuista, la infancia es definida como una etapa. Como un corte en el tiempo que da ciertos atributos, posibilidades y limitaciones. Desde el criterio cronológico, las etapas están dadas por la edad y en la medida en que ésta cambia van cambiando las atribuciones que se le pueden hacer. Por ejemplo, dos niños plantearon:

- Niño: ¿qué es ser niño? Es una etapa de cada persona, la etapa es una etapa (colegio 1). Inv. 2: ¿Qué es ser niño y que es ser niña?

- Niña 1: es una etapa cuando uno es pequeño, digámoslo así y es más o menos antes de la adolescencia y después de que uno es bebé, más o menos (colegio 2).

- Niño: la infancia para mí es algo como, uno puede jugar cada rato, hace sus tareas. En cambio si fuera adulto, pues trabaje para los hijos, y yo cada rato hago tareas y me voy a jugar fútbol o veo televisión.

- Niño: para mí ser niño es tener uno el derecho de estudiar, de jugar (risas), de tener un techo y ver televisión y que a uno no le prohíban hacer nada.

- Niña: pues ser niño es una etapa como decía Rafico, pues ser niño es ser divertido y ya...

- Niña 3: para mí son los años en que nos enseñan cómo prepararnos a la vida, a los años de trabajo, a todo eso.
Este criterio de comprender la infancia como una etapa, estadio, momento de la vida distinto a los demás, atraviesa todos los significados. Se constituye en una constante, en que se diferencia la infancia y la adultez casi como un corte artificial, en el que cambian las situaciones, las vivencias, los significados, las actividades, los roles y, por supuesto, las responsabilidades. La infancia desde el criterio discontinuista, entonces, conlleva a pensar que el desarrollo se da por fases y que hay saltos entre uno y otro, casi como que el ingreso a una etapa implica el olvido de la anterior, como se observa en los otros criterios.

Desde el criterio psicosocial, la infancia fue relacionada con funciones y acciones que se pueden desarrollar en esta etapa. Se hacen comparaciones entre las funciones, entre la vida infantil y adulta, entre la infancia anterior y la actual.

En cuanto a las funciones en la vida infantil y adulta se diferencia al niño del adulto, el primero juega y el segundo trabaja. Desde esta perspectiva, parece que el ingreso a la vida adulta estuviera muy marcado por la responsabilidad, muy propio de los procesos de globalización. Entonces, la infancia tiene tareas como: jugar, divertirse, "pasarla bien".

- Profesor 1: “La infancia debería ser ternura, juego, amor, acunación, como un amor maternal muy, muy, muy intenso, eso debería ser la infancia" (colegio 1).

- Niño: “La infancia para mí es algo como, uno puede jugar cada rato, hace sus tareas. En cambio, si fuera adulto, pues trabaje para los hijos, y yo cada rato hago tareas y me voy a jugar fútbol o veo televisión". 
- Niño: "Para mí ser niño es tener uno el derecho de estudiar, de jugar, (risas) de tener un techo y ver televisión y que a uno no le prohíban hacer nada (colegio 4)

En lo social, se encuentran también lecturas relacionadas con los derechos explícitamente. Los niños y niñas asocian el significado de infancia, con el concepto de derechos, los cuales se van perdiendo o van siendo menos importantes en la medida en que avanza el desarrollo.

- Niño: "Uno tiene derecho a estudiar, a que lo respeten y uno a respetar" (colegio 4)

- Niña 2: "Cuando nosotros somos niños tenemos más derechos que cuando adulto, no tenemos tantas responsabilidades y es una etapa antes de la adolescencia donde podemos disfrutar mucho más" (colegio 5).

- Niña 6: “Cuando tú eres pequeño tienes menos responsabilidades que cuando estás grande, cuando estás grande no es que tengas más derechos, sino que tienes más responsabilidades" (colegio 5).

La categoría derecho es explícita en los niños y en las niñas y no en los adultos, estos últimos la usan implícitamente. Posiblemente la inclusión de esta categoría pueda estar relacionada con la difusión que han realizados los medios de comunicación en los últimos años sobre los derechos de la infancia y la adolescencia, o posiblemente por discusiones y espacios académicos que puedan estar vivenciando los niños en la escuela.

Por otra parte, la categoría derecho es incluida en la significación como la opuesta de responsabilidad, opuesta al deber ser: “los niños tienen derechos y los adultos responsabilidades".

Rincón (2007) plantea que comprender el niño o la niña como sujetos de derechos, es necesario para comprender la infancia en toda su complejidad, es decir, desde sus deberes y responsabilidades también.

En este mismo criterio se reconocen los cambios en la infancia. Éstos son evidentes para los sujetos frente a su propia infancia (padres y maestros de treinta a cincuenta años). Tanto padres como maestros atribuyen estos cambios a los desarrollos tecnológicos; precisamente, Jaramillo (2007) plantea que con la modernidad se instaura unan nueva concepción de infancia, como una categoría de experiencias distintas a las de la categoría adulto. En la investigación, los adultos plantean que los niños y niñas de ahora están más informados, tienen acceso a equipos que ellos nunca tuvieron, pueden establecer comunicaciones lejanas con otros en menor tiempo; entre otros aspectos. Entre los dispositivos tecnológicos más mencionados está la Internet; incluyendo en ella los juegos en línea, la práctica del chateo, manejo de facebook, el correo electrónico y todas las páginas a las cuales pueden acceder los niños y las niñas. Además, señalan la televisión por cable y los juegos electrónicos. Estos dispositivos son referidos independientemente del colegio y la diferencia parece estar en qué tanto acceso puede tener un niño a ellos. Algunos niños cuentan con los dispositivos en su casa, otros deben buscarlos en el café del barrio o los conocen a través de la escuela.

Para los adultos sujetos de la investigación estos dispositivos hacen que la infancia de "hoy" se viva de una manera diferente y 
uno de esos aspectos diferentes tiene que ver con la velocidad de los procesos. Peralta (2003), expresa:

En efecto, los escenarios donde se desenvuelven las niñas y los niños se han renovado en el nuevo siglo. Junto con lo que acontece en sus contextos naturales próximos y en sus culturas de pertenencia, los medios de información, comunicación y de transporte han acercado espacios, tiempos, objetos y personas que anteriormente estaban muy distantes de la experiencia de un párvulo (p. 1).

En la investigación enuncian que los niños y las niñas de ahora conocen y tienen información que ellos no tenían a su edad, y no sólo eso, que vivencian fenómenos que esperarían en otra etapa del ciclo vital.

Profesora 5: y en cuanto a lo que es vivir la infancia yo creo que los chicos de hoy en día se saltan demasiadas etapas, no viven, por la misma velocidad de la globalización no viven cada una de sus etapas en un proceso normal, sino que cuando menos piensa uno están viviendo cosas de niños de 10 años o de 15 años o inclusive de 20 [...] a niños de 7 años haciendo relaciones interpersonales con chicos de 15 y 16 años cuando anteriormente no se veía eso, estaba muy bien demarcado las diferencias de las edades, cada uno con su grupo entonces como que llamémosla así, esa frontera que había ya ha dejado de existir [...] yo puedo hacer cualquier cosa, entonces en el momento en que yo puedo hacer cualquier cosa, o puedo respetar al otro o puedo pasar por encima del otro y en cuando a qué les sobra yo creo que son demasiado ávidos, demasiado, demasiado [...] por decirlo así, porque no es una etapa que se deba saltar y ya los chicos de hoy en día van más allá, van más rápido que uno, entonces uno se pone a mirar 10 años atrás, inclusive como era uno y uno esta súper quedado en comparación a ellos (se ríe, la mayoría del tiempo ha hecho cara de asombro) (Colegio 1).

En estos relatos de algunas madres se evidencia cómo significan el desarrollo acelerado con la información a la que tienen acceso los niños y las niñas y cómo éste se da también a través de la educación formal, pues conocimientos que ellos estudiaron en un grado más avanzado se ven en este momento en un grado inferior.

Madre 1: yo pienso que hoy todos los niños nos llevan mil pasos adelante, respecto a todo, hoy los niños de quinto saben cosas que nosotros aprendimos en sexto de bachillerato (los demás lo corroboran), física y las tareas de no sé qué cosa de... igual a uno le toca de papá estar ahí haciendo eso porque... [varios padres comentan al tiempo], le toca hacer un circuito, y compre los cables y la pila y uno dice miércoles en quinto de primaria son cuantos, escasamente tu veías escasamente [no se entiende, se ríen], son cosas que uno no, inclusive uno ha aprendido mucho conocimiento a través de los niños que hemos estado con ellos en ese periodo en el que uno le ayuda con tareas y todo eso (Colegio 5).

Según los padres, estos cambios constituyen un dispositivo que acelera el desarrollo. Desde esta perspectiva, los cambios sociales, se convierten en un gatillador de procesos en los niños y las niñas. Desde estas significaciones valdría la pena preguntarse qué tan acertadas son las teorías del desarrollo discontinuistas, que establecen etapas y fases, y algunos procesos que cumplir en ellas. Ésta es una invitación a actualizar las teorías del desarrollo. Peralta (2003) expresa que estos cambios no solamente son culturales, sino que también tiene que ver con desarrollos en otro orden: 
A los vertiginosos cambios culturales se suma también el mayor conocimiento de las potencialidades de los niños pequeños, en especial aquellos derivados de los aportes de las neurociencias y de la psicología cognitiva. Sabemos que los niños puedan aprender más que todo lo que antes se postulaba y que los primeros dos años son esenciales para la conformación del "cableado neuronal" que va a sostener todo tipo de comportamientos y aprendizajes en su vida presente y posterior (p. 2).

Los dispositivos tecnológicos son considerados por padres y profesores de los colegios que tienen estudiantes provenientes de estratos 3,4 y 5 como la posibilidad de tener acceso a otras culturas. Además de reconocer que en la infancia el acceso a éstos moviliza el desarrollo, plantean que les "abre puertas", amplía su horizonte de sentido y les da facilidades de insertarse en otros mundos. Y los profesores ubican las limitaciones de estos dispositivos en la imposibilidad de filtrar información a la que el niño tiene acceso.

- Profesora 1: “Pues la tecnología es buena [no se entiende], se están cerrando únicamente a lo que le da un computador o a lo que le da los avances tecnológicos" (colegio 6).

- Profesor 3: "Es como dice la profesora, nada es malo todo depende del uso o de la manera como uno utilice las cosas, entonces el Internet, buenísimo, pero siempre y cuando en los niños y en lo jóvenes sea orientado, pero la gran mayoría de las familias de hoy día pocas veces comparten con sus hijos" (Colegio 4).

Así como ven la tecnología como un "gatillador" del desarrollo, como apertura a otros horizontes, algunos padres y maestros evidencian temores frente a ésta. El uso de la tecnología, en especial Internet y los juegos interactivos, son asociados como pérdida de tiempo, como un obstáculo para establecer relaciones sociales, como un factor de aislamiento y encerramiento, lo cual les puede preocupar en algunos casos. Este aislamiento también es explicado por Bromberg (2007), en su artículo Infancia, comunicación y ciudad, como parte de la cultura urbana, en la que se ha roto la convivencia por diferentes motivos. Sin embargo, la preocupación no es por la uniformización que a veces estimula estos tipos de medios de comunicación:

- Profesora: "Realmente pienso que es lo más importante, ellos dejan de ser niños, en segundo de primaria ya se acabó la niñez, uno fue niño hasta los doce años por lo menos, ya en tercero de primaria están pensando cosas totalmente diferentes a las que..., ya no hay juego, o sea como que se le va a uno la imaginación porque obviamente ya le han robado muchísimo, no sé, de pronto la mente de los niños ya como que está más avanzada [...] Algo súper importante, entonces ya como que no sueñan, no imaginan, no crean, todo se lo ponen en bandeja de plata".

- Madre 1: "Yo pienso que todos los niños nos llevan pasos adelante [...] ¿pero qué han perdido de años acá?, el juego, el compartir más personalmente [los demás lo asientan], la creatividad totalmente, no totalmente pero sí la creatividad de antes que uno se imaginaba cualquier ladrillo y un carro" (Colegio 5).

Como se expresa en estos relatos, los padres se preocupan porque los avances tecnológi- 
cos pueden estar apresurando el desarrollo o dificultándolo. En otro relato, la preocupación se centra en la violencia de los medios y cómo pueden brindar modelos negativos para la infancia.

- Madre 2: "Cuando entran a la Internet o hacen los juegos están apresurados en hacer, en pasar mundos, etc., etc., sin embargo eso nos lleva a muchos problemas, nos hacen niños agresivos, vemos en nuestro mundo que cuando ellos salen a jugar están imitando lo que están viendo en los juegos entonces se pegan muy fuerte, se pelean de manera agresiva, eh..." (Colegio 1).

- Profesor: "Desde chiquitos ellos están atentos de llenar el álbum, saber conocer el nombre de todos los jugadores de todos los países, pero todo esto nos acarrea un problema ¿no? por ejemplo las barras bravas algo que adoptamos que no era nuestro y ya pues en el país tenemos muchas dificultades a través de eso, adoptamos barras bravas, de Argentina de otros países que nos están afectando, eso es como lo más... visto en la educación" (Colegio1).

Bromberg (2007) se pregunta, en su ponencia en el congreso de Infancia y Comunicación cuáles son los espacios en los que se da la socialización del niño. Plantea cómo ese espacio de interacción familiar está reducido, generalmente la comunicación es sobre las tareas. Antes se enunciaba la importancia de la socialización primaria y secundaria, la una relacionada con la familia y la otra con la escuela, ahora es fundamental hablar de otra socialización, la de los medios de comunicación.
Los padres también evidencian diferencias entre la niñez de antes y la de ahora, y estas diferencias están atravesadas por significaciones de heteronomía versus autonomía. Los niños y las niñas de antes seguían más las instrucciones de sus padres y hacían lo que éstos les plantearan. Los niños y las niñas de ahora cuestionan, exigen y toman decisiones.

- Madre 4: “Es que antes ser niño o ser niña era ponerse lo que la mamá le ponía a uno, si te ponían moñas son moñas y ya, en cambio ahora ser niño ser niña es lo que ellos pidan, lo que ellos exijan".

- Madre 5: "Anteriormente las niñas se dejaban poner vestido, ya ahorita no, quieren sus pantaloncitos pegaditos, sus chorcitos corticos, sus minifaldas; ya los vestiditos largos con mediecita velada eso ya pasó para ellas, igual para los niños, ya no se dejan vestir sino que quieren pantalones anchos o pantalones por debajo, entonces, las cosas van cambiando mucho. Ya los hijos son los que parecen que fueran independientes".

- Madre 1: "Son autónomos".

Es importante revisar si las acciones de los niños y de las niñas como toma de decisiones realmente están atravesadas por autonomía o por inversión en la jerarquía de poder. Los niños y niñas tienen poder en sus hogares y este poder les permite exigir ciertos aspectos de la cultura actual y al parecer está dado por el dominio de la información y de la tecnología:

Respecto a lo que éramos antes, pues francamente los niños y niñas ya son como adultos que interactúan con cosas de adultos, que a propósito, creo que nos llevan bastante ventaja en términos del uso de la tecnología y la 
forma como navegan y como transitan en un mundo que en muchos sentidos para nosotros es desconocido y que llegar a conocerlo[...] Como lo mencionaba antes, para nosotros como hijos la gran preocupación de nuestras mamás era ver cómo nos metían a la casa, porque era delicioso estar con los amigos jugando en la cuadra y jugando tapas y una cantidad de cosas que nosotros ya dejamos en la historia y después con nuestros hijos más pequeños, [...] creo que es al revés, los adultos son los que más difícilmente nos cuesta aprender un proceso, los jóvenes [...] con alguna dificultad, pero los niños van volando y es al revés, los niveles de grande habilidad y grande dominio de los conceptos de informática, pues son los niños y ellos ahora saben más que nosotros (Colegio 5).

Estos cambios acelerados se pueden comprender desde el concepto de desarrollo de Vigotsky, vigente aún, en el cual, definitivamente, los cambios sociales halan el desarrollo del individuo. En alguna forma los medios de comunicación, la tecnología, en la actualidad, se han constituido como en aquella zona de desarrollo próximo, que facilita que los niños y las niñas piensen de una manera distinta en este mundo global..., tal vez su pensamiento también lo es.

Los adultos observan estos cambios en los niños y en las niñas, también la familia y la escuela se ha modificado. La familia se ha modificado radicalmente, Giddens (1999) plantea una categoría para hablar de esta institución, las instituciones concha: "se llaman igual pero han cambiado sus características básicas" (p. 72). En este mismo sentido, el autor afirma que las actitudes y la protección hacia ellos también han cambiado.

Desde el criterio ideal, se puede considerar la infancia como una etapa o periodo en el que se presenta o no conflicto, una tendencia que marca entonces los significados de la infancia como algo perfecto y otros como algo conflictivo, pero que no lo debiera ser, en esta última la infancia como ideal es un objeto por alcanzar, es una utopía. Al respecto una madre plantea:

Para mí ser niño, primero es que mis hijos se puedan divertir, que no tengan preocupación ni ningún tipo de problema, o sea, que no estén dentro de nuestros problemas familiares, o sea sí, que sean niños, que sean libres, que tengan la oportunidad reír, de soñar, para mí eso es ser niño o sea, tener niñez [...] para mí concepto es la mejor etapa de la vida porque cuando son niños puedo jugar, puedo brincar, puedo hacer de todo y no me tengo que preocupar, mientras que uno de adulto se hace responsable y tiene que ser responsable (Madre colegio 2).

Como se observa en esta narrativa, la infancia es una etapa sin problemas, sin responsabilidades. Sin embargo, cabe la pena preguntarse a qué tipo de interacciones lleva esta significación, si la infancia es una etapa sin responsabilidades, cómo se pueden ir construyendo los procesos de autonomía, o también cómo comprenden estos adultos las dificultades que se le pueden presentar a un niño o una niña. Al respecto otro padre plantea:

El concepto de la niñez es como soñar, como tener ilusiones, como pensar en que la vida es un juego, es algo muy bonito, lo que debo recrear, mi hijo ve la vida como un juego, como algo muy bonito que él debe vivir, ése es el mensaje que él siempre me ha dado a mí, su expresión, su alegría que me ha llevado a pensar que la niñez es como un sueño, un sueño feliz, ese es el concepto que mi hijo me ha enseñado a mí o mis hijos, porque yo tengo dos pequeños, 
de los que es la niñez, ese es mi concepto (Padre, colegio 1).

Este tipo de lecturas desde el criterio ideal plantea la infancia casi como ausente de algunas características humanas como el enfrentar y resolver problemas, en los cuales no es posible el conflicto y si éste aparece debe ser evitado; porque puede causar daño. Las significaciones de este tipo, pueden llevar a ignorar o a minimizar las dificultades que vivencia el niño y la niña.

Como se observa en estas narraciones, estas significaciones están relacionadas con ideales que a veces se alejan del niño real concreto, que también sufre angustias, temores, dificultades y que además de sentir emociones dulces también agrede. Este mismo tipo de resultados se encontraron en la investigación realizada por Rincón (Santamaría \& Barreto, 2007). En esta investigación la autora describe los imaginarios de maestros y maestras en formación acerca de la infancia. La autora cita la tendencia anteriormente mencionada como el mito de la infancia como inocencia y la caracteriza de la siguiente manera:

Otra forma de representación es la idea de niños y niñas asociadas a sentimiento de "ternura", "felicidad", "amor", "libertad" y "desarrollo", estas ideas muestran una noción de la niñez aprendida seguramente en su experiencia como madres, padres o hermanos mayores, representación en la que se usan adjetivos calificativos que no reconocen al niño en su complejidad como ser, o configuran la idea de niños de niñas como seres incompletos. Desde esta perspectiva el niño también aparece como sinónimo de pureza, de bondad natural, de lo bueno (p. 151).

Estas significaciones se mantienen en los profesores, que ubican a la niñez en una eta- pa como un ideal; sin embargo, reflexionan acerca de cómo ese ideal es imposible en la actualidad, se constituye como una utopía. Investigadora 1: “ $¿$ Es posible que los niños ahorita no tienen eso?" Profesora 1: "No en absoluto, la vez pasada les hablábamos eso, ustedes saben perfectamente que en este momento no hay mamá, no hay papá, no hay infancia, con padres muy difícil" (Colegio 1).

Algunas niñas coinciden con la significación, pero incluyen las responsabilidades como parte de la infancia:

- Niña 2: “Cuando nosotros somos niños tenemos más derechos que cuando adulto, no tenemos tantas responsabilidades y es una etapa antes de la adolescencia donde podemos disfrutar mucho más" (Colegio 5).

- Niña: "Niña es... dedicarme mi tiempo para jugar, para estudiar, para divertirme, para hacer mis tareas y para ser responsable" (Colegio 5).

Otro grupo de significaciones se asocia con la infancia como imagen de vulnerabilidad, de fragilidad. Profesora 6: "En la primera pregunta donde dice qué es ser niño y que es ser niña actualmente, para mí es ser vulnerable, siento que los niños son muy vulnerables, vulnerables a todo, empezando, al papá y a la mamá, o sea, siento que los adultos somos muy agresivos con los niños y así seamos papá y mamá somos muy agresivos, entonces creo que la vulnerabilidad es igual a ser niño y a ser niña" (Colegio 1).

En este relato se observa que la vulnerabilidad se relaciona directamente con la función y las acciones de padre y madre hacia los niños y las niñas. En los siguientes re- 
latos se hace énfasis nuevamente en la familia, específicamente a la ausencia de ésta.

- Profesora 6: "Yo siento que ahorita son más vulnerables sobre la soledad, entonces antes un niño vivía con su familia y con su mamá y su mamá le decía todo el tiempo estaba pendiente de él y le decía todo el tiempo te amo, te quiero, bueno en fin ahorita está solo, ahorita son hijos de apartamento, entonces cualquiera que le diga venga mire este dulce, mire cómo está de lindo, estás hermoso como te quiero [suena el timbre] ya para ese niño es alguien que lo quiere y por eso se convierte en ser vulnerable ¿si?, eh... precisamente ahí como que contesta la otra pregunta ¿Cómo era la infancia ahora y como era la infancia antes? Igual, más vulnerable por la escasez de afecto, siento yo que es por la gran escasez de afecto que tienen ahora. Lo mismo la siguiente: ¿qué es lo que más les hace falta? ¿Familia y amor sí?, y ¿Qué les sobra? Información y soledad" (Colegio 5).

- Profesora 3: “Yo veo que para los niños el no tener sus progenitores cerca, el no tener sus abuelos o sus familiares sí les está generando un sentirse no amados porque ellos sí se tienden a comparar; de pronto uno escucha los niños es que el mayor dolor que yo tengo es que a mi compañerito lo recibe el papá cuando se baja de la ruta [una compañera hace un sonido de corroboración mmm...] y a mí a veces me recibe mi vecina; él sí se siente y, de hecho, uno sí les escucha eso o, por ejemplo, es que 'yo no soy tan inteligente' entonces uno le dice: porque no eres tan inteligente, es que yo veo que no tengo papá que me ayude a hacer las tareas y yo no soy tan inteligente y van relacionando el amor y la 'presencia del adulto con su propio desarrollo y su propio desempeño, o yo no soy, yo no sé hacer eso profesora, entonces uno dice: no anímate que lo sabes hacer, no es que a mí yo no sé sacar la punta del lápiz en cambio a él le sacan el viene con los lapicitos bien organizados" (Colegio 1).

Los significados de vulnerabilidad (colegios 1, 5 y 6), están dados más por los maestros y los han anclado a la situación de la familia actual: ambos padres trabajadores, familias mono parentales, familias con múltiples ocupaciones, estrés en los padres y falta de redes sociales presenciales (amigos de barrio). Giddens (1999) plantea que una minoría de personas vive como la familia ideal en que papá y mamá están presentes, el padre gana y la madre está en casa:

En algunos países más de una tercera parte de todos los nacimientos tienen lugar fuera del matrimonio mientras que la proporción de gente que vive sola ha crecido exorbitantemente $y$ parece probable que lo haga aún más. En muchas sociedades, como Estados Unidos o Gran Bretaña, el matrimonio sigue siendo muy popular -se han calificado adecuadamente, como sociedades de mucho divorcio y mucho matrimonio- (p. 71).

Por todo lo que hay que pensar sobre la infancia actual, es necesario pensar la familia de otra forma; comprendiendo los diferentes tipos de familia en la actualidad y las funciones que ahora desarrollan sus miembros.

La tendencia a comprender la infancia desde la vulnerabilidad, también la encuentra Rincón (2007) en su estudio con maestros en formación, sin embargo, los imaginarios 
estudiados por la autora están más anclados a situaciones de pobreza que hace la niñez vulnerable:

[...] los niños tienden a ser representados como objetos de lástima, de piedad y de control. La otra cara de sus vidas se invisibiliza, aquella de sus sueños, de sus potencialidades, de sus capacidades, de esta manera no vemos la posibilidad de que sean protagonistas. Se observa, la presencia de un imaginario asistencialista y proteccionista, imaginarios que impiden que los estudiantes se comprometan con el desarrollo del conocimiento (p. 150).

Aunque las significaciones en el presente estudio fueron asociadas con la ausencia de familia y en el de Rincón con pobreza, el sentido de los niños desde la vulnerabilidad conlleva a acciones de los adultos de sobreprotección y de asistencia, más que de fortalecimiento de procesos autónomos. Cuando un profesor tiene la significación de los niños como pobrecitos, porque no tienen familia todo el tiempo, puede empezar a interactuar con el niño tratando de llenar esa ausencia o inclusive de desestimarlo y pensar que no tiene recursos por la carencia que presenta.

Finalmente, los significados relacionados con el género se evidenciaron más en los niños y niñas que en los adultos. Esto se atribuye a que durante la investigación, a los niños y niñas les inquietó mucho la diferencia que se hacía de género en las preguntas “¿Quién es un niño o una niña, hoy?”. Con los adultos se realizó la misma diferencia, sin embargo, ellos generalizaron los niños y las niñas, bajo un solo tipo de significación.

Se observa en las respuestas de los niños y las niñas que ellos encuentran marcadas diferencias entre los géneros no sólo por la significación, sino también por lo que hacen y cómo lo hacen. En algunas de estas significaciones se observa la tensión entre los dos géneros y la comprensión de cada uno de ellos desde el déficit del otro:

Respuestas de los niños:

- "Pues las niñas son muy picadas y... y que, y también se meten con los niños".

- "Como ellas, ellas dos que, que es bonitas pero son más picadas qué malas amigas".

- "Se la pasan pegándole a los niños".

- “'Son groseras!”

- "Sí, porque es que ellas dos, nosotros nada más (en tono de risa), sí... ellas les pegan a las niñas y nosotros no les hacemos nada a veces".

Las niñas plantean:

- "A mí me parece que los niños son totalmente diferentes, porque a los niños les gusta jugar brusco y a las niñas no y a veces los niños como que cuando juegan con las niñas a veces las niñas salen llorando, yo digo eso porque a mí me ha pasado".

- "Los niños y las niñas sí somos diferentes en algunas cosas. Estoy de acuerdo con Valentina, a veces... o sea, que las niñas somos más delicadas, entonces como que ellos abusan de su fuerza y nos pegan, también son como demasiado buenas personas" (Colegio 6).

Estas diferencias de género son explícitas en niños y niñas de los colegios de estrato 4,5 y 6 , en los otros estratos, esta diferencia no fue explícita. 


\section{Conclusiones}

Los significados de infancia están constituidos desde criterios discontinuistas, psicosociales, ideales, de vulnerabilidad y de género. En discontinuista se agrupan los significados que comprenden la infancia como etapa. En lo psicosocial significados relacionados con funciones, derechos y cambios. En ideales significaciones relacionados con la infancia como época sin problemas. En vulnerabilidad se agrupan significados relacionados con dificultades y minusvalías y en género diferencias entre niños y niñas.

En cuanto a los significados discontinuistas, éstos consideran la infancia como una etapa o periodo de tiempo, que se diferencia de otras por los papeles y las responsabilidades. La infancia, como etapa, permea todas las demás significaciones de infancia, puesto que siempre para referirse a ella establecen comparaciones en términos de ciclos.

Desde criterios psicosociales se hace énfasis en las funciones de los niños y las niñas, los derechos de éstos, los cambios generacionales y la vulnerabilidad. Frente a las funciones de los niños y niñas éstas se relacionan más con el juego, la diversión, estudiar; en contraposición con los adultos que se dedican a actividades laborales.

La categoría derecho es incluida explícitamente por los niños y por las niñas, en los adultos de la investigación ésta permanece implícita. Derecho es opuesto por los niños y niñas a la responsabilidad y suponen que en la infancia hay derechos y en la adultez responsabilidades. En los adultos esta categoría es implícita, relacionando la infancia como ausencia de responsabilidades y con énfasis en los derechos.
Los adultos, perciben cambios entre la niñez de ellos y la actual, éstos se dan por el acceso a diferentes medios de información, como Internet, televisión, entre otros. Estos medios según los adultos se han convertido en "gatilladores" del desarrollo, haciendo que el desarrollo de las generaciones actuales tenga un ritmo más rápido.

La vulnerabilidad surge también como categoría en las significaciones sobre infancia. La vulnerabilidad es puntuada por los maestros y maestras para referirse a la niñez actual. Ésta se da por condiciones de soledad en familias mono parentales y en familias con padres trabajadores.

La infancia también es significada como ideal, una etapa en la que no debe existir conflicto y si lo hay éste debe ser evitado. Estas significaciones pueden llevar minimizar los conflictos de los niños y de las niñas y hasta descalificar sus sentimientos.

En cuanto al género, son los niños y las niñas las que significan las diferencias: los adultos para hablar de ellos, los generalizan bajo la categoría niño y desde allí establecen características generales. Los niños y las niñas hacen diferencias de género a partir de actitudes y comportamientos observados en la cotidianidad.

Con base en estos hallazgos, son indudables los cambios que están sucediendo en torno a la infancia; así se hace evidente la necesidad de repensar la categoría infancia desde los dispositivos actuales, desde los cambios que están emergiendo y desde las nuevas culturas productos de la globalización. Esto conlleva que la psicología reflexione sobre sus teorías del desarrollo y empiece a replantearlas de acuerdo con los niños y con las niñas actuales. 


\section{REFERENCIAS}

Arias, F. (Sin fecha). Educación en la globalización: un cambio en la perspectiva. Revista Latinoamericana de Ciencias Sociales, niñez y juventud. Recuperado el 25 de octubre de 2007 de: www.umanizales.edu.co/revistacinde/index.html.

Arriagada, I. (2004). Estructuras familiares, trabajo y bienestar en América Latina. En I. Arriagada \& V. Aranda (Comp.). Cambio de las familias en el marco de las transformaciones globales: necesidad de políticas públicas eficaces. Santiago, CEPAL: División de desarrollo social, 45.

Arrieta E. \& Maiz, I. (1999). Interacción social y contextos educativos. Revista de psicodidáctica. Recuperado el 27 de octubre de 2007 de: http://redalyc.uaemex. mx/redalyc/pdf/175/17500905.pdf

Bruner, J. (1991) Actos de significado mas allá de la revolución cognitiva. Madrid: Alianza.

Bruner, J. (1999) Globalización cultural y modernidad. Chile: Fondo de Cultura Económica.

García, N. (1999). La globalización imaginada. México: Paidós

Carli, S. (2005). Infancia, cultura y educación en las décadas del 80 y 90 en Argentina. Recuperado el 14 de noviembre de 2007 de: www.redalyc.com.

Chilina, C. (2007). Estudio descriptivo, comparativo y relacional del desarrollo infantil integral en una muestra de niños y niñas de diferentes edades, niveles socioeconómicos y regiones de Venezuela. Revista ORBIS / Ciencias Humanas. Recuperado el 14 de noviembre de 2007 de: http://www.ucm.es/info/polinfan/2006/ area-lectura/mod-1/pilotti_contextodel-texto.pdf OEA Año 3 / № 7 /.
Espino \& López (2005) Zer, 19 Los niños en la publicidad. Una propuesta de categorización de las representaciones sociales sobre la infancia en los anuncios televisivos. Recuperado el 14 de noviembre de 2007 de: http://www.ehu.es/zer/zer19/zer19_7. pdf

Flores (Sin fecha). La infancia como emblema paradigmático. Recuperado de: http:// www.reflexiones.fcs.ucr.ac.cr/documentos/61/la_infancia.pdf.

Fornet- Betancourt (2003). Culturas y poder: interacción y asimetría entre las culturas en el contexto de la globalización. España: Desclée de Brower.

Giddens, A. (1999). Un mundo desbocado. Los efectos de la globalización en nuestras vidas. Taurus: Madrid.

Jaramillo, L. (2007). Concepción de infancia. Revista del Instituto de Estudios Superiores en Educación Universidad del Norte. Recuperado de: http://ciruelo.uninorte. edu.co/pdf/zona_proxima/8/9_Concepcion\%20de\%20infancia.pdf № 8 .

Joseff, B. (2005). El estudio de la infancia desde la psicología cultural: un encuentro de perspectivas. Avances en Psicología Latinoamericana, 23, Universidad Autónoma del estado de México. Recuperado de: http://redalyc.uaemex.mx.

Jurado, J. (2003) Problemáticas socioeducativas de la infancia y la juventud contemporánea. Revista Iberoamericana de Educación, 31.

Kaye, K. (1986). La vida mental y social del bebé. Barcelona: Paidós.

Pillotti. S. (2001) Serie políticas sociales. Globalización y convención sobre los derechos del niño: el contexto del texto. Chile: Pu- 
blicación de las Naciones Unidas. Recuperado el 14 de noviembre de 2007 de: http://www.cepal.org/cgi-bin/getProd. asp?xml=/publicaciones/xml/4/7024/ P7024.xml\&xsl=/dds/tpl/p9f.xsl\&base=/ redima/tpl/top-bottom.xslt

Peralta, M. (2003). Los desafíos de la educación infantil. Recuperado el 2 de marzo de 2009 de: http://www.futurolaboral.cl/ FL/docs/soc_conoc/Peralta_preescolar. pdf.

Rincón, C. (2002). Infancia y comunicación. Memorias. Bogotá: Universidad Distrital Francisco José de Caldas.

Sierra, L. (2003). Globalización, multiculturalismo y comunicación. En J. Pereira \& M. Villadiego (Ed.). Comunicación, cultura y globalización. Bogotá: Centro Editorial Javeriano (CEJA)-UNESCO.

Tobón, S. (2004). Formación basada en competencias: pensamiento complejo, diseño curricular y didáctica. Bogotá: ECOE.
UNICEF. (2006) Globalización e Infancia. Oficina Regional para América Latina y el Caribe. Unidad de Políticas Públicas. Panamá, República de Panamá.

Urreiztieta, M. (2004) La sociología interpretativa: globalización y vida cotidiana. Red Revista Espacio Abierto. Caracas: Universidad Simón Bolívar. Recuperado el 1 de noviembre de 2007 de: http:// site.ebrary.com/lib/bibliotecaustasp/ Doc?id=10103172\&ppg=5.

Vaca, P. \& Romero, D. (2007). Construcción de significados frente a los contenidos violentos de los videojuegos en niños de 11 a 14 años. Acta colombiana de Psicología, 10 (1), 35-48.

Vygotsky, L. (1996) El desarrollo de los procesos psicológicos superiores. Barcelona: Crítica.

Wertsch, J. (1995). Vygotsky y la formación social de la mente. Barcelona: Paidós. 